\title{
An umbrella review on the effects of diabetes on implant failure and peri-implant diseases
}

\author{
Jonathan MEZA MAURÍCIO(a) \\ Tamires Szeremeske MIRANDA(a) (iD \\ Mariana Linhares ALMEIDA(a) \\ Helio Doyle SILVA(a) \\ Luciene Cristina FIGUEIREDO(a) (iD) \\ Poliana Mendes DUARTE(a) \\ (a) Universidade de Guarulhos - UNG, \\ Dental Research Division, Department of \\ Periodontology, Guarulhos, SP, Brazil.
}

Declaration of Interests: The authors certify that they have no commercial or associative interest that represents a conflict of interest in connection with the manuscript.

Corresponding Author:

Poliana Mendes Duarte

E-mail: poliduarte@yahoo.com

hitps://doi.org/10.1590/1807-3107bor-2019.vol33.0070

Submitted: June 5, 2019

Accepted for publication: June 13, 2019

Last revision: June 19, 2019

\begin{abstract}
The aim of this review is to summarize the evidence on associations between diabetes mellitus (DM) and complications around dental implants. Electronic database searches of MEDLINE, EMBASE, JBI Database of Systematic Reviews and Implementation Reports, Cochrane Database of Systematic Reviews and the PROSPERO register were performed from 1990 up to and including May 2018, using MeSH terms and other keywords. Systematic reviews and meta-analyses investigating the associations of DM and implant complications (failure, survival, bone loss, peri-implant diseases, and post-surgery infection) were eligible. The quality of the included reviews was determined using the Assessment of Multiple Systematic Reviews Tool 2 (AMSTAR 2). Twelve systematic reviews were included. Implant survival rates ranged from $83.5 \%$ to $100 \%$, while implant failure rates varied from $0 \%$ to $14.3 \%$ for subjects with DM. The three meta-analyses performed for event "implant failure" reported no statistically significant differences between diabetic and non-diabetic subjects. An apparently increased risk of peri-implantitis is reported in patients with DM. According to the AMSTAR 2 classification, $50 \%$ of the reviews were classified as being of "critically low", $25 \%$ as of "low" and $25 \%$ as of "moderate" quality. Evidence indicates high levels of survival and low levels of failure of implants inserted in patients with DM. However, DM was assessed as a whole in the majority of studies and, the actual influence of hyperglycemia on implant survival/failure is still uncertain. DM/hyperglycemia seems to be associated with a high risk of peri-implantitis. However, this conclusion is based on a limited number of systematic reviews.
\end{abstract}

Keywords: Diabetes Mellitus; Hyperglycemia; Dental Implants; Peri-Implantitis.

\section{Introduction}

Dental implants are currently the most consistent and successful treatment for the rehabilitation of edentate individuals. Overall, high success rates of implant-supported rehabilitation have been reported in the literature, ${ }^{1,2}$ however, regrettably, early and late implant failures and peri-implant complications are still challenges in clinical practice. Therefore, there is interest in identifying the risk factors related to implant 
losses and other complications, including lifestyles and systemic diseases.

Diabetes mellitus (DM) is a major public health problem worldwide that is growing in prevalence and is associated with severe complications. It was estimated that, in 2017, approximately 450 million adults were affected with DM globally and this prevalence is expected to increase to 693 million by 2045. ${ }^{3}$ Although most clinicians feel that diabetic subjects may experience more problems around dental implants than systemically-healthy subjects, the actual impact of DM on implant survival and complication rates remains controversial. Most studies in animals have demonstrated that DM adversely affects bone healing around implants. ${ }^{4,5,6}$ Some clinical studies have reported minor or no associations of DM with implant failures, ${ }^{7,8}$ while others have showed higher losses of dental implants and peri-implant diseases in diabetics than in non-diabetic subjects. ${ }^{910,11}$

To date, several systematic reviews have tried to elucidate the weight of evidence of the possible effects of DM around dental implant, including peri-implant diseases, bone loss and early and late implant losses. However, an overview compiling all evidence from the existing systematic reviews on this topic have not been performed so far. Therefore, the aim of this study is to summarize the evidence on associations between DM and complications around dental implants, using an umbrella review approach.

\section{Methodology}

\section{Review question}

"Do subjects with DM experience more early and late dental implant failures/complications than nondiabetic subjects?"

\section{Search strategy}

A comprehensive approach to literature searching was used to identify all relevant systematic reviews and meta-analyses investigating the association of DM and dental implant failures/ complications. Electronic database searches of MEDLINE, EMBASE, JBI Database of Systematic Reviews and Implementation Reports, the Cochrane
Database of Systematic Reviews and the PROSPERO register were performed from 1990 up to and including May 2018, using MeSH terms and other keywords. The following terms were used in the search strategy: review OR systematic OR metaanalysis AND diabetes OR DM OR diabetes mellitus OR hyperglycemia OR glycemia OR glycated hemoglobin OR glycemic control AND dental implants OR osseointegration OR peri-implant disease OR peri-implantitis OR periimplantitis OR implant disease OR implant infection OR implant failure OR late implant failure OR early implant failure OR implant survival. Two investigators (TSM and MLA) independently examined the titles and abstracts of the shortlisted systematic reviews and meta-analyses to decide on eligibility. The full texts of the papers, considered by title and abstract to be pertinent, were then assessed. Subsequently, the same two investigators (TSM and MLA) performed a hand search of the references from available systematic reviews and meta-analyses. All selected articles were evaluated by two authors (TSM and MLA) and classified as appropriate, or not, for inclusion in this umbrella review. Disagreements were resolved by consensus and with discussion with a third investigator (PMD).

\section{Inclusion criteria}

Systematic reviews, with or without meta-analyses, published in English from 1990 up to and including May 2018 that included studies, performed in humans, on the effects of DM on early and late implant failures and complications.

\section{Exclusion criteria}

Primary or original clinical research, abstracts, animal studies, in vitro studies, case reports, case series, letters to the editor and narratives, other types of non-systematic reviews (e.g., critical reviews, overviews, state-of-the-art reviews).

\section{Data extraction}

Predefined data collection worksheets were used for the evaluation of each selected publication. The data from each systematic review included were extracted by one author (JMM) and entered 
directly into tables that were checked for accuracy by a second researcher in an independent fashion (PMD). The following data were extracted; authors and year of publication, number and design (case series, retrospective, prospective, controlled clinical trial, cross-sectional, etc.) of the studies included in the systematic reviews, presence or absence of meta-analysis, type of DM evaluated in studies included, follow up, outcome studied in the systematic reviews (failure, survival, bone loss, peri-implant diseases, post-surgery infection) and main conclusions.

\section{Assessment of the quality of the studies included}

The evaluation of the methodological quality of the systematic reviews and meta-analyses included was performed using the Assessment of Multiple Systematic Reviews (AMSTAR 2) tool. ${ }^{12}$ The included reviews were appraised by two examiners (JMM and TSM) independently. For each systematic review included, the 16 questions of the AMSTAR 2 checklist were responded on the AMSTAR 2 site (https://amstar.ca/Amstar_Checklist.php) by each examiner using 'yes', 'partial yes', 'no' or in some cases 'not applicable'. All information relating to the included papers was gathered based on what the systematic reviews and meta-analyses reported. Once the filling of the AMSTAR 2 checklist was completed, a final categorization of the systematic reviews was generated to classify them as of high, moderate, low or critically low quality (https:// amstar.ca/Amstar_Checklist.php). Once this process had been completed independently, the two examiners (JMM and TSM) met to decide on a final judgment for each study by consensus. When necessary, persistent disagreements were solved by discussion with a third investigator (PMD).

\section{Results}

Figure presents the Flowchart for the selection of the papers. The search strategy identified 932 potentially eligible papers from all electronic databases. After removal of duplicate articles and screening of titles and abstracts, 18 full-text publications were comprehensively evaluated. Six studies were excluded ${ }^{13-18}$ because they did not fulfill the inclusion criteria (Table 1). Twelve systematic reviews $19,20,21,22,23,24,25,26,27,28,29,30$ were included in this umbrella review (Table 2).

The characteristics and main findings of the systematic reviews included are presented in Table 2. The systematic reviews were published between 2006 and 2017. A total of 53 primary studies were assessed by the systematic reviews included. The number of studies entered in these systematic reviews varied from 2 to 22 . The study designs of the studies evaluated by the systematic reviews varied considerably, ranging from case reports to RCT. Meta-analyses were performed in only four ${ }^{21,22,25,26}$ of the 12 systematic reviews included. Two systematic reviews ${ }^{19,23}$ included data from animals and humans but only the human data were considered in this umbrella review. Four systematic reviews 20,25,28,30 $^{2}$ evaluated the effects of DM and other risk factors (e.g., smoking, radiotherapy, osteoporosis, obesity, cardiovascular diseases, rheumatoid arthritis, etc.), but only DM findings were considered in the current review. The majority of systematic reviews comprised studies evaluating subjects with type 1 and 2 DM. 19,21,22,24,25,26,27,29

Table 1. List of the excluded reviews.

\begin{tabular}{|c|c|}
\hline Study & Reason for exclusion \\
\hline Fiorenilli et al. $2000^{13}$ & Narrative review \\
\hline Diz et al. $2013^{14}$ & Narrative review \\
\hline Borba et al. $2013^{15}$ & Narrative review focused on antibiotics \\
\hline Hurst et al. $2014^{16}$ & Article comment \\
\hline Fontanari et al. $2014^{17}$ & Systematic review focused on implant surface \\
\hline Shi et al. $2016^{18}$ & Systematic review focused on the comparison between well-controlled and poorly-controlled diabetic patients \\
\hline
\end{tabular}


Table 2. Characteristics and main findings of the systematic reviews included.

\begin{tabular}{|c|c|c|c|c|c|c|c|}
\hline Systematic review & $\begin{array}{l}\mathrm{N}^{\circ} \text { of } \\
\text { studies } \\
\text { included }\end{array}$ & $\begin{array}{l}\text { Designs of } \\
\text { the studies } \\
\text { included }\end{array}$ & Meta-analysis & $\begin{array}{l}\text { Follow-up } \\
\text { (Months) }\end{array}$ & $\begin{array}{l}\text { Type of } \\
\text { DM }\end{array}$ & $\begin{array}{l}\text { Outcome } \\
\text { studied }\end{array}$ & Main findings \\
\hline $\begin{array}{l}\text { Kotsovilis et al. } \\
2006^{19}\end{array}$ & 8 & PS, RS and CS & No & 6 to 204 & | and || & $\begin{array}{l}\text { Implant survival } \\
\text { rates }\end{array}$ & $\begin{array}{l}\text { Implant survival rates in the } \\
\text { included studies varied from } \\
83.5 \% \text { to } 100 \% \text {. }\end{array}$ \\
\hline $\begin{array}{l}\text { Klokkevoled \& } \\
\text { Han } 2007^{20}\end{array}$ & 4 & $\begin{array}{l}\text { PS, RS and } \\
\text { Case series }\end{array}$ & No & 12 to 144 & $\|$ & $\begin{array}{l}\text { Implant survival } \\
\text { rates }\end{array}$ & $\begin{array}{c}\text { Implant survival rates in the } \\
\text { included studies varied from } 88 \% \\
\text { to } 94.3 \% \text {. }\end{array}$ \\
\hline $\begin{array}{l}\text { Javed et al. } \\
2009^{23}\end{array}$ & 10 & $\begin{array}{l}\text { PS, RS, CS and } \\
\text { Cross-sectional } \\
\text { study }\end{array}$ & No & $\begin{array}{l}\text { Not } \\
\text { mentioned }\end{array}$ & $\|$ & Not clear & $\begin{array}{l}\text { The summary of the main findings } \\
\text { reported by the authors are not } \\
\text { coherent with the results presented } \\
\text { in the papers included in the } \\
\text { systematic review. }\end{array}$ \\
\hline $\begin{array}{l}\text { Oates et al. } \\
2011^{24}\end{array}$ & 16 & $\begin{array}{l}\text { Cases series, } \\
R C \text { and } P C\end{array}$ & No & 12 to 252 & | and || & $\begin{array}{l}\text { Implant failure } \\
\text { rates }\end{array}$ & $\begin{array}{c}\text { Implant failure rates in the } \\
\text { included studies varied from } 0 \% \\
\text { to } 14.3 \% \text {. }\end{array}$ \\
\hline Chen et al. $2013^{25}$ & 5 & PS and RS & Yes & 24 to 144 & | and II & $\begin{array}{l}\text { Implant failure } \\
\text { rates }\end{array}$ & $\begin{array}{c}\text { Implant failure rates in the } \\
\text { included studies varied from } 0 \% \\
\text { to } 8.9 \% \text {. }\end{array}$ \\
\hline $\begin{array}{l}\text { Charcnovic et al. } \\
2014^{26}\end{array}$ & 14 & $\begin{array}{c}\text { RS, CCT and } \\
\text { RCT }\end{array}$ & Yes & 3 to 204 & | and || & $\begin{array}{l}\text { Implant failure } \\
\text { rates }\end{array}$ & $\begin{array}{c}\text { Implant failure rates in the } \\
\text { included studies varied from } 0 \% \\
\text { to } 11.11 \% \text {. }\end{array}$ \\
\hline $\begin{array}{l}\text { Annibali et al. } \\
2016^{27}\end{array}$ & 7 & $\begin{array}{l}\text { PS, RS, Case } \\
\text { series and RCT }\end{array}$ & No & 24 to 78 & I and || & $\begin{array}{l}\text { Implant survival } \\
\text { rates }\end{array}$ & $\begin{array}{c}\text { Implant survival rates in the } \\
\text { included studies varied from } \\
100 \% \text { to } 87.7 \% \text {. }\end{array}$ \\
\hline $\begin{array}{l}\text { Guobis et al. } \\
2016^{28}\end{array}$ & 6 & $\begin{array}{l}\text { PS, RS and } \\
\text { RCT }\end{array}$ & No & 2.2 to 108 & $\begin{array}{l}\text { Not } \\
\text { mentioned }\end{array}$ & $\begin{array}{l}\text { Not consistent } \\
\text { for title, aim and } \\
\text { results }\end{array}$ & $\begin{array}{l}\text { Difficulty summarizing the findings } \\
\text { based on the information reported } \\
\text { by the authors. }\end{array}$ \\
\hline \multirow{3}{*}{$\begin{array}{l}\text { Naujokat et al. } \\
2016^{29}\end{array}$} & \multirow{3}{*}{22} & \multirow{3}{*}{$\begin{array}{c}\text { PS, RS and } \\
\text { Cross-sectional } \\
\text { study. }\end{array}$} & \multirow{3}{*}{ No } & \multirow{3}{*}{4 to 144} & \multirow{3}{*}{ I and || } & \multirow{3}{*}{$\begin{array}{l}\text { Postoperative } \\
\text { complications, } \\
\text { peri-implantitis, } \\
\text { and implant } \\
\text { survival. }\end{array}$} & $\begin{array}{l}\text { Implant survival rates in the } \\
\text { included studies varied from } \\
85.6 \% \text { to } 100 \% \text {. }\end{array}$ \\
\hline & & & & & & & $\begin{array}{l}\text { The majority of the studies } \\
\text { included focusing on } \\
\text { peri-implantitis demonstrated an } \\
\text { association between DM and } \\
\text { increased risk of peri-implant } \\
\text { inflammation and bone loss. }\end{array}$ \\
\hline & & & & & & & $\begin{array}{l}\text { No findings of postoperative } \\
\text { complications were reported }\end{array}$ \\
\hline Turri et al. $2016^{30}$ & 2 & $\begin{array}{l}\text { RS and } \\
\text { Cross-sectional } \\
\text { study }\end{array}$ & No & 12 to 168 & $\|$ & $\begin{array}{l}\text { Peri-implant } \\
\text { diseases (Peri- } \\
\text { implantitis) }\end{array}$ & $\begin{array}{l}\text { Difficulty summarizing the findings } \\
\text { based on the information reported } \\
\text { by the authors. }\end{array}$ \\
\hline \multirow{2}{*}{$\begin{array}{l}\text { Moraschini \& } \\
\text { Barboza } 2016^{21}\end{array}$} & \multirow{2}{*}{14} & \multirow{2}{*}{$\begin{array}{l}\text { PS, RS and } \\
\text { CCT }\end{array}$} & \multirow{2}{*}{ Yes } & \multirow{2}{*}{3 to 204} & \multirow{2}{*}{ | and || } & \multirow{2}{*}{$\begin{array}{l}\text { Implant survival } \\
\text { rates }\end{array}$} & $\begin{array}{c}\text { Implant survival rates in the } \\
\text { included studies varied from } 91 \% \\
\text { to } 100 \% \text {. }\end{array}$ \\
\hline & & & & & & & $\begin{array}{c}\text { A single study reported a very low } \\
\text { implant survival rate of } 31.8 \% \\
\text { (Loo et al. 2009). }\end{array}$ \\
\hline \multirow[t]{2}{*}{$\begin{array}{l}\text { Monje et al. } \\
2017^{22}\end{array}$} & \multirow[t]{2}{*}{12} & \multirow[t]{2}{*}{$\begin{array}{l}\text { PC, } \mathrm{RC} \text { and } \\
\text { Cross-sectional } \\
\text { study }\end{array}$} & \multirow[t]{2}{*}{ Yes } & \multirow[t]{2}{*}{12 to 198} & \multirow[t]{2}{*}{ | and || } & \multirow{2}{*}{$\begin{array}{l}\text { Peri-implant } \\
\text { diseases } \\
\text { (peri-implant } \\
\text { mucositis and } \\
\text { peri-implantitis). }\end{array}$} & $\begin{array}{l}\text { The risk of peri-implantitis was } \\
\text { about } 50 \% \text { higher in subjects with } \\
\text { DM than in non-diabetic subjects } \\
\text { (relative risk of } 1.46 \text { and odds } \\
\text { ratio of } 1.89 ; p<.001 \text { ). }\end{array}$ \\
\hline & & & & & & & $\begin{array}{l}\text { The risk of peri-implantitis but not } \\
\text { mucositis was significantly greater } \\
\text { in subjects with hyperglycemia. }\end{array}$ \\
\hline
\end{tabular}

PS: prospective study; RS: retrospective study; CS: clinical study; CR: Case report; CCT: controlled clinical trial; RCT: randomized clinical trial; PC: prospective cohort; RC: retrospective cohort; DM: diabetes mellitus 


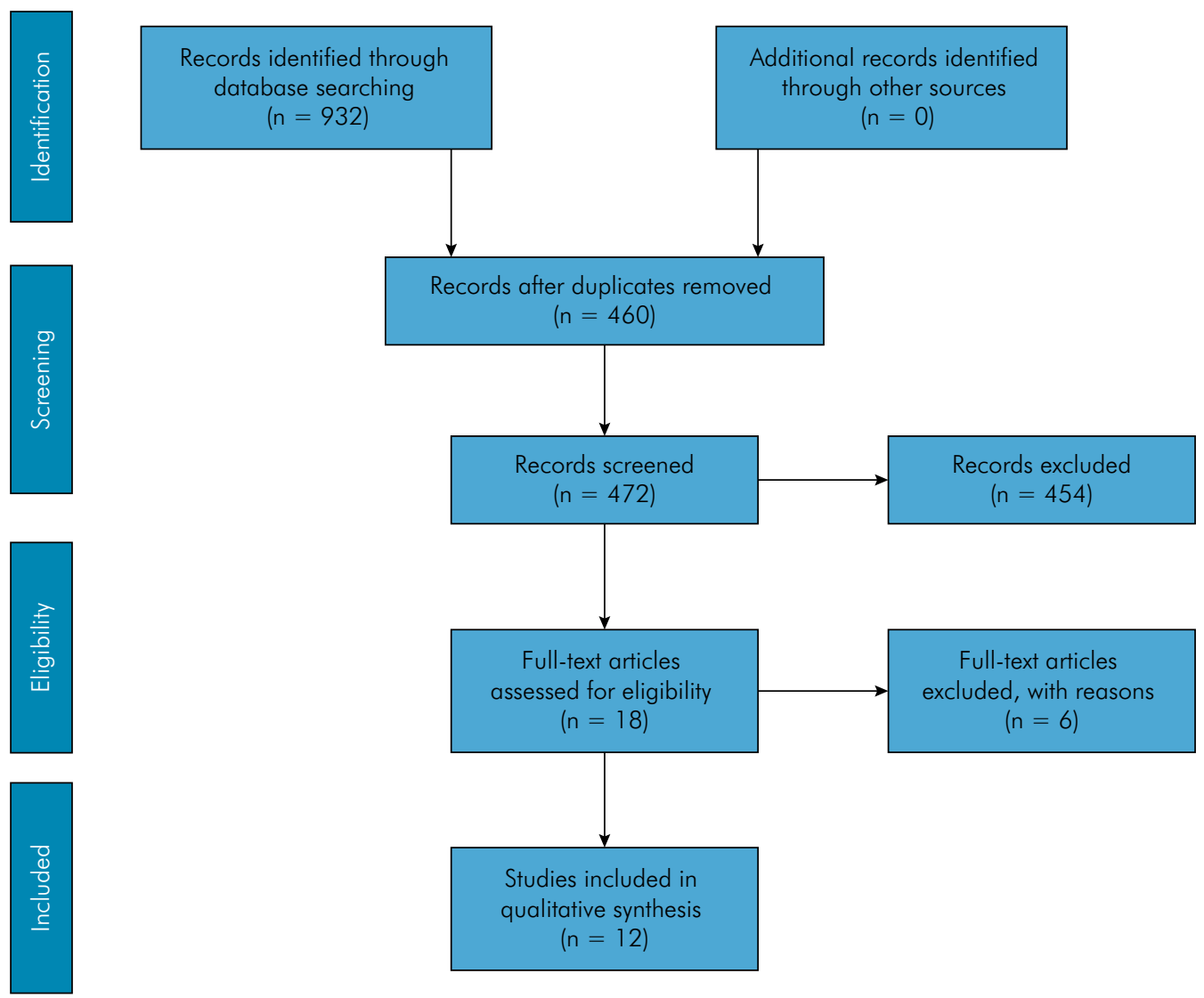

Figure. Flowchart of the selection of the papers.

Seven systematic reviews focused on the evaluation of the effects of DM on implant survival/ failure. ${ }^{19,20,21,24,25,26,27}$ One systematic review evaluated the effects of DM on postoperative complication, peri-implantitis and implant survival. ${ }^{29}$ Two of the systematic reviews concentrated on studies evaluating the association of DM and peri-implant diseases. ${ }^{22,30}$ The outcomes studied were not clear in two studies ${ }^{23,28}$ (Table 2). The implant survival rates ranged from $83.5 \%$ to $100 \% 19,20,21,27,29$ while implant failure rates varied from $0 \%$ to $14.3 \%$ in subjects with DM. A single study, ${ }^{31}$ included in Moraschini and Barboza, ${ }^{21}$ reported a very low implant survival rate of $31.8 \%$ in subjects with DM. The three studies ${ }^{21,25,26}$ that performed meta-analyses for the event "implant failure rate" reported no statistically significant differences between diabetic and non-diabetic subjects (Table 3). According to two studies, ${ }^{22,29}$ an apparently increased risk of peri-implantitis may occur in patients with DM.
The only review ${ }^{22}$ that performed a meta-analysis for the "peri-implantitis" event demonstrated a statistically significant higher risk of disease for subjects with hyperglycemia (Table 3), considering also reports that exclude smokers. Main findings were difficult to summarize and interpret in three of the 12 systematic reviews included. $23,28,30$

Table 4 provides the AMSTAR 2 qualification of evidence for the systematic reviews included. In terms of quality of evidence, about $50 \%$ were rated as being of "critically low" quality 19,20,23,24,26,30 and 25\% as "low" quality,,$^{27,28,29}$ according to the AMSTAR 2 classification. Twenty-five percent of the reviews were graded as of "moderate"21,22,25 quality, while none of the systematic reviews included achieved a "high" quality grade. Only two studies ${ }^{22,28}$ contained an explicit statement that the review methods were established prior to conducting the review (item 2). Risk of bias (item 9) was correctly assessed by five systematic reviews. ${ }^{21,22,25,29,30}$ 
Table 3. Results of the meta-analysis for the events "implant failure" and "peri-implantitis", reported by the four reviews that performed quantitative analysis.

\begin{tabular}{llccc}
\hline Study & Event & p-value & Risk ratio & $95 \% \mathrm{Cl}$ \\
\hline Chen et al. $2013^{25}$ & Implant failure & 0.07 & 0.90 & $0.62-1.32$ \\
Charcnovic et al. $2014^{26}$ & Implant failure & 0.65 & 1.07 & $0.80-1.44$ \\
Moraschini \& Barboza $2016^{21}$ & Implant failure & 0.34 & 1.56 & $0.62-3.91$ \\
Monje et al. $2017^{22}$ & Peri-implantitis & $<0.04$ & 3.36 & $1.06-10.81$ \\
\hline
\end{tabular}

Table 4. Assessment of the methodological quality of the systematic reviews included, using the AMSTAR 2 instrument.

\begin{tabular}{|c|c|c|c|c|c|c|c|c|c|c|c|c|c|c|c|c|c|}
\hline \multirow{2}{*}{ Systematic review } & \multicolumn{16}{|c|}{ AMSTAR 2 item } & \multirow{2}{*}{ Quality of evidence } \\
\hline & 1 & 2 & 3 & 4 & 5 & 6 & 7 & 8 & 9 & 10 & 11 & 12 & 13 & 14 & 15 & 16 & \\
\hline Kotsovilis et al. $2006^{19}$ & $\mathrm{~N}$ & $\mathrm{~N}$ & $\mathrm{~N}$ & $P / Y$ & Y & Y & $\mathrm{N}$ & Y & $\mathrm{N}$ & $\mathrm{N}$ & - & - & $N$ & $\mathrm{~N}$ & - & $N$ & Critically low \\
\hline Klokkevoled \& Han $2007^{20}$ & $\mathrm{~N}$ & $\mathrm{~N}$ & $\mathrm{~N}$ & $\mathrm{~N}$ & $\mathrm{~N}$ & $\mathrm{~N}$ & $P / Y$ & $P / Y$ & $\mathrm{~N}$ & $N$ & - & - & $\mathrm{N}$ & $\mathrm{N}$ & - & $\mathrm{N}$ & Critically low \\
\hline Javed et al. $2009^{23}$ & $\mathrm{~N}$ & $\mathrm{~N}$ & $N$ & $\mathrm{~N}$ & Y & $N$ & $P / Y$ & $N$ & $\mathrm{~N}$ & $N$ & - & - & $N$ & $N$ & - & Y & Critically low \\
\hline Oates et al. $2011^{24}$ & $\mathrm{~N}$ & $\mathrm{~N}$ & Y & $\mathrm{N}$ & Y & $\mathrm{N}$ & Y & $\mathrm{N}$ & $\mathrm{N}$ & $N$ & - & - & $\mathrm{N}$ & Y & - & $\mathrm{N}$ & Critically low \\
\hline Chen et al. $2013^{25}$ & $\mathrm{~N}$ & N & Y & $P / Y$ & Y & Y & Y & Y & Y & $N$ & Y & Y & Y & Y & Y & Y & Moderate \\
\hline Charcnovic et al. $2014^{26}$ & Y & $\mathrm{N}$ & Y & $P / Y$ & Y & $\mathrm{N}$ & $\mathrm{N}$ & Y & $\mathrm{N}$ & $\mathrm{N}$ & Y & $\mathrm{N}$ & $N$ & Y & Y & Y & Critically low \\
\hline Annibali et al. $2016^{27}$ & $\mathrm{~N}$ & $\mathrm{~N}$ & Y & $P / Y$ & Y & Y & Y & Y & $P / Y$ & $\mathrm{~N}$ & - & - & Y & $N$ & - & Y & Low \\
\hline Guobis et al. $2016^{28}$ & $\mathrm{~N}$ & Y & Y & $P / Y$ & Y & $\mathrm{N}$ & $\mathrm{N}$ & Y & $P / Y$ & $N$ & - & - & Y & $\mathrm{N}$ & - & $N$ & Low \\
\hline Naujokat et al. $2016^{29}$ & Y & $\mathrm{N}$ & Y & $P / Y$ & $\mathrm{~N}$ & $N$ & $N$ & Y & Y & Y & - & - & $N$ & $N$ & - & Y & Low \\
\hline Turri et al. $2016^{30}$ & Y & $\mathrm{N}$ & Y & $\mathrm{N}$ & $\mathrm{N}$ & Y & $\mathrm{N}$ & $\mathrm{P} / \mathrm{Y}$ & Y & $\mathrm{N}$ & - & - & $\mathrm{N}$ & $N$ & - & Y & Critically low \\
\hline Moraschini \& Barboza $2016^{21}$ & Y & $P / Y$ & Y & Y & Y & $N$ & Y & Y & Y & $N$ & Y & Y & Y & $N$ & Y & Y & Moderate \\
\hline Monje et al. $2017^{22}$ & Y & Y & Y & Y & Y & Y & Y & Y & Y & $\mathrm{N}$ & Y & $N$ & Y & Y & $\mathrm{N}$ & Y & Moderate \\
\hline
\end{tabular}

Y: yes; $N$ : no; $P / Y$ : partial yes; - : without meta-analyses

\section{AMSTAR 2 domains}

1. Did the research questions and inclusion criteria for the review include the components of PICO?

2. Did the report of the review contain an explicit statement that the review methods were established prior to conduct the review and did the report justify any significant deviations from the protocol?

3. Did the review authors explain their selection of the study designs for inclusion in the review?

4. Did the review authors use a comprehensive literature search strategy?

5. Did the review authors perform study selection in duplicate?

6. Did the review authors perform data extraction in duplicate?

7. Did the review authors provide a list of excluded studies and justify the exclusions?
8. Did the review authors describe the included studies in adequate detail?

9. Did the review authors use a satisfactory technique for assessing the risk of bias (RoB) in individual studies that were included in the review?

10.Did the review authors report on the sources of funding for the studies included in the review?

11.If meta-analysis was performed did the review authors use appropriate methods for statistical combination of results?

12. If meta-analysis was performed, did the review authors assess the potential impact of $\mathrm{RoB}$ in individual studies on the results of the meta-analysis or other evidence synthesis?

13. Did the review authors account for RoB in individual studies when interpreting/ discussing the results of the review? 
14.Did the review authors provide a satisfactory explanation for, and discussion of, any heterogeneity observed in the results of the review?

15. If they performed quantitative synthesis, did the review authors carry out an adequate investigation of publication bias (small study bias) and discuss its likely impact on the results of the review?

16. Did the review authors report any potential sources of conflict of interest, including any funding they received for conducting the review?

\section{Discussion}

With the increasing number of systematic reviews published, an important next step to provide a highlevel weight of evidence to guide clinical practice is the performance of a review of the existing systematic reviews. Therefore, to our knowledge, this is the first attempt to comprehensively summarize and perform a critical appraisal and quality assessment of available evidence related to the effects of DM on early and late dental implant complications in humans. Twelve systematic reviews were included in this umbrella review, comprising 53 primary studies. Overall, most systematic reviews included estimated the effects of DM on implant survival/failure, indicating high levels of survival and low levels of failure of implants inserted in patients with DM. With regard to periimplant diseases, evidence suggests an increased risk of peri-implantitis in patients with hyperglycemia. However, the number of systematic reviews on the relationship between DM and peri-implant diseases is still limited. Using a critical appraisal tool for systematic reviews (AMSTAR 2), the quality of the systematic reviews included in this umbrella review was found to range from "critically low" to "moderate", with the quality of evidence for half of the reviews classified as "critically low".

Interest has been demonstrated by researchers and clinicians for establishing whether and, to what extent, DM negatively influences implant survival/ failure. The eight reviews ${ }^{19-21,24,25,26,27,29}$ that clearly reported the percentage of implant survival/failure demonstrated high survival $(83.5 \%$ to $100 \%)$ and low implant failure ( $0 \%$ to $14.3 \%$ ) in patients with
DM, considering a follow-up of 2.2 to 252 months. Such rates are close to those reported by previous systematic reviews focusing on non-diabetic patients $(\sim 95.0 \%)$ that were followed-up for at least 10 years. ${ }^{32,33}$ Therefore, according to the current evidence, DM does not appear to considerably reduce the percentage of dental implant survival and, therefore, it seems safe to place dental implants in patients with DM.

Several studies corroborate the concept that hyperglycemia is one of the most important risk factors for periodontitis. ${ }^{34}$ Considering the similarities between periodontal and peri-implant diseases in terms of etiology, pathogenesis and clinical features, it has been supposed that DM could also affect the course of peri-implant diseases. Therefore, it is important to ascertain scientifically whether and, to what extent, DM negatively affects the onset and progression of peri-implant diseases. An unexpected finding of this umbrella review is that, to date, only three systematic reviews have compiled data on this topic. ${ }^{22,29,30}$ Two of these $\mathrm{e}^{29,30}$ performed only qualitative analysis of a small number of studies and provided insubstantial conclusions on the relationship between DM and peri-implant diseases. The most consistent systematic review on this subject ${ }^{22}$ presented qualitative analyses of 12 studies and quantitative analyses of seven studies. The authors revealed that the risk of periimplantitis, but not mucositis, is significantly greater in subjects with hyperglycemia, compared to those with normal glycemia. However, the current umbrella review indicates that there is still scarce evidence in the literature to support an actual and strong association between DM and peri-implant diseases.

Over recent years, several critical appraisal instruments have been proposed to evaluate different aspects of systematic reviews and meta-analyses. AMSTAR 2 is a well-recognized tool used to assess systematic reviews that include randomized or nonrandomized studies. This instrument has seven crucial domains (items 2, 4, 7, 9, 11, 13 and 15) that can critically influence the quality of a review and the validity of its conclusions. The current umbrella review found that, according to AMSTAR 2 , none of the reviews included were classed as of 'high' quality and, only three were deemed as of "moderate" quality (Table 3). Notably, the 
majority of the reviews were considered as "low" or "critically low" in quality, signifying that these reviews failed to provide adequate details of their methods, including registration of study protocol, adequacy of the literature search, justification for excluding individual studies, assessment of the risk of bias of primary studies, appropriateness of metaanalytical methods, consideration of risk bias when interpreting the results, assessment of presence and possible impact of publication bias, among others. Therefore, unfortunately, the majority of systematic reviews included in this umbrella review might not be relied on for providing an accurate conclusion regarding the relationship between DM and implant survival/failure and peri-implant diseases.

In addition to the methodological weaknesses of the systematic reviews that were highlighted by the AMSTAR 2, the current findings should be interpreted with caution due to several methodological variations and flaws in the systematic reviews included and their respective primary studies. Firstly, the number of papers included in the systematic reviews varied greatly (from 2 to 22), indicating a great heterogeneity in the inclusion and exclusion criteria of the primary articles. The few systematic reviews that adequately assessed risk of bias ${ }^{21,22,25,29,30}$ demonstrated that most of the primary studies did not follow all methodological standards, as none achieved the maximum score for the risk of bias and quality assessments. The duration of DM and implant surface, implant material and implant design also varied considerably among studies. Some systematic reviews evaluated only type $2 \mathrm{DM}$ while others evaluated both type 1 and type 2 diabetic subjects. Most importantly, several studies failed to report on the glycemia of the diabetic patients at the time of implant placement and during the follow-up period, while others evaluated only diabetic patients with acceptable/controlled glycemia. This might be a possible explanation as to why the majority of systematic reviews found no or little effect of DM on implant survival. Another major drawback of the primary papers included in the systematic reviews was the lack of standard case definitions for periimplant diseases and the lack of agreement on the definitions of implant success, survival and failure criteria, which were sometimes incorrectly used as equivalent. Furthermore, the prevalence of failure/ survival was reported at the patient level in some primary studies and at the implant level in others.

One limitation of the current umbrella systematic review is that a quantitative analysis could not be conducted, due to the small number of systematic reviews with meta-analyses (Table 3). Furthermore, ideally, conclusions should be made based on only systematic reviews with a high quality of evidence, but the reviews included were classified as being of "critically low" to "moderate" quality. Main directions for future systematic reviews and primary studies on the possible effects of DM on dental implants should include: 1- clear reporting of the glycemic status of the patients; 2 - the following of available guidelines for reporting studies in order to increase their qualities.

\section{Conclusions}

The actual evidence indicates high levels of survival and low levels of failure of implants inserted in patients with DM. However, DM was assessed as a whole in the majority of studies and, the actual influence of hyperglycemia on the survival/failure of implants is still uncertain. Furthermore, DM/ hyperglycemia seems to be associated with a high risk of peri-implantitis. However, this conclusion is based on a limited number of systematic reviews and primary articles. The majority of systematic reviews presented are of weak quality.

\section{References}

1. Jung RE, Zembic A, Pjetursson BE, Zwahlen M, Thoma DS. Systematic review of the survival rate and the incidence of biological, technical, and aesthetic complications of single crowns on implants reported in longitudinal studies with a mean follow-up of 5 years. Clin Oral Implants Res. 2012 Oct;23 Suppl 6:2-21. https://doi.org/10.1111/i.1600-0501.2012.02547.x 
2. Derks J, Schaller D, Håkansson J, Wennström JL, Tomasi C, Berglundh T. Effectiveness of implant therapy analyzed in a Swedish population. J Dent Res.2015 Mar 11;94(3_suppl):44-51S. https://doi.org/10.1177/0022034515608832

3. Cho NH, Shaw JE, Karuranga S, Huang Y, Fernandes JDR, Ohlrogge AW, et al. IDF Diabetes Atlas: global estimates of diabetes prevalence for 2017 and projections for 2045. Diabetes Res Clin Pract. 2018 Apr;138:271-81. https://doi.org/10.1016/i.diabres.2018.02.023

4. Giglio MJ, Giannunzio G, Olmedo D, Guglielmotti MB. Histomorphometric study of bone healing around laminar implants in experimental diabetes. Implant Dent. 2000;9(2):143-9. https://doi.org/10.1097/00008505-200009020-00006

5. Takeshita F, Murai K, lyama S, Ayukawa Y, Suetsugu T. Uncontrolled diabetes hinders bone formation around titanium implants in rat tibiae. A light and fluorescence microscopy, and image processing study. J Periodontol. 1998 Mar;69(3):314-20. https://doi.org/10.1902/jop.1998.69.3.314

6. Nevins ML, Karimbux NY, Weber HP, Giannobile W V, Fiorellini JP. Wound healing around endosseous implants in experimental diabetes. https://doi.org/10.1016/S1079-2104(99)70236-2

7. Al Amri MD, Abduljabbar TS. Comparison of clinical and radiographic status of platform-switched implants placed in patients with and without type 2 diabetes mellitus: a 24 -month follow-up longitudinal study. Clin Oral Implants Res. 2017 Feb;28(2):226-30. https://doi.org/10.1111/clr.12787

8. Al Amri MD, Abduljabbar TS, Al-Kheraif AA, Romanos GE, Javed F. Comparison of clinical and radiographic status around dental implants placed in patients with and without prediabetes: 1-year follow-up outcomes. Clin Oral Implants Res. 2017 Feb;28(2):231-5. https://doi.org/10.1111/clr.12788

9. Morris HF, Ochi S, Winkler S. Implant survival in patients with type 2 diabetes: placement to 36 months. Ann Periodontol. 2000 Dec;5(1):157-65. https://doi.org/10.1902/annals.2000.5.1.157

10. Ferreira SD, Silva GL, Cortelli JR, Costa JE, Costa FO. Prevalence and risk variables for peri-implant disease in Brazilian subjects. J Clin Periodontol. 2006 Dec;33(12):929-35. https://doi.org/10.1111/j.1600-051X.2006.01001.x

11. Daubert DM, Weinstein BF, Bordin S, Leroux BG, Flemming TF. Prevalence and predictive factors for peri-implant disease and implant failure: a cross-sectional analysis. J Periodontol. 2015 Mar;86(3):337-47. https://doi.org/10.1902/jop.2014.140438

12. Shea BJ, Reeves BC, Wells G, Thuku M, Hamel C, Moran J, et al. AMSTAR 2: a critical appraisal tool for systematic reviews that include randomised or non-randomised studies of healthcare interventions, or both. BMJ. 2017 Sep;358:14008. https://doi.org/10.1136/bmi.j4008

13. Fiorellini JP, Nevins ML. Dental implant considerations in the diabetic patient. Periodontol 2000. 2000 Jun;23(1):73-7. https://doi.org/10.1034/i.1600-0757.2000.2230106.x

14. Diz P, Scully C, Sanz M. Dental implants in the medically compromised patient. J Dent. 2013 Mar;41(3):195-206. https://doi.org/10.1016/i.jdent.2012.12.008

15. Borba AM, Souza DF, Brozoski MA, Burim RA, Naclério-Homem MG, Deboni MC. Can the use of antibiotics interfere with the success of dental osseointegrated implants in diabetic patients? J Contemp Dent Pract. 2013 Nov;14(6):1197-201. https://doi.org/10.5005/ip-journals-10024-1476

16. Hurst D. Evidence unclear on whether Type I or II diabetes increases the risk of implant failure. Evid Based Dent. 2014 Dec;15(4):102-3. https://doi.org/10.1038/sj.ebd.6401057

17. Fontanari LA, Oliveira GJPL, Basso TLD, Marcantonio Junior E, Perez Orrico SR, Sampaio JEC. The influence of different implant surfaces on osseointegration in diabetes: a systematic review of the literature. Minerva Stomatol. 2014 Apr;63(4):127-33.

18. Shi $Q, X u J$, Huo N, Cai C, Liu H. Does a higher glycemic level lead to a higher rate of dental implant failure?: A meta-analysis. J Am Dent Assoc. 2016 Nov;147(11):875-81. https://doi.org/10.1016/i.adaj.2016.06.011

19. Kotsovilis S, Karoussis IK, Fourmousis I. A comprehensive and critical review of dental implant placement in diabetic animals and patients. Clin Oral Implants Res. 2006 Oct;17(5):587-99. https://doi.org/10.1111/j.1600-0501.2005.01245.x

20. Klokkevold PR, Han TJ. How do smoking, diabetes, and periodontitis affect outcomes of implant treatment? Int J Oral Maxillofac Implants. 2007;22 Suppl:173-202.

21. Moraschini V, Barboza ES, Peixoto GA. The impact of diabetes on dental implant failure: a systematic review and meta-analysis. Int J Oral Maxillofac Surg. 2016 Oct;45(10):1237-45. https://doi.org/10.1016/j.ijom.2016.05.019

22. Monje A, Catena A, Borgnakke WS. Association between diabetes mellitus/hyperglycaemia and peri-implant diseases: systematic review and meta-analysis. J Clin Periodontol. 2017 Jun;44(6):636-48. https://doi.org/10.1111/icpe.12724

23. Javed F, Romanos GE. Impact of diabetes mellitus and glycemic control on the osseointegration of dental implants: a systematic literature review. J Periodontol. 2009 Nov;80(11):1719-30. https://doi.org/10.1902/jop.2009.090283

24. Oates TW, Huynh-Ba G, Vargas A, Alexander P, Feine J. A critical review of diabetes, glycemic control, and dental implant therapy. Clin Oral Implants Res. 2013 Feb;24(2):117-27. https://doi.org/10.1111/j.1600-0501.2011.02374.x

25. Chen H, Liu N, Xu X, Qu X, Lu E. Smoking, radiotherapy, diabetes and osteoporosis as risk factors for dental implant failure: a meta-analysis. Baradaran HR, editor. PLoS One. 2013 Aug;8(8):e71955. https://doi.org/10.1371/journal.pone.0071955 
An umbrella review on the effects of diabetes on implant failure and peri-implant diseases

26. Chrcanovic BR, Albrektsson T, Wennerberg A. Diabetes and oral implant failure: a systematic review. J Dent Res. 2014 Sep;93(9):859-67. https://doi.org/10.1177/0022034514538820

27. Annibali S, Pranno N, Cristalli MP, La Monaca G, Polimeni A. Survival analysis of implant in patients with diabetes mellitus: a systematic review. Implant Dent. 2016 Oct;25(5):663-74. https://doi.org/10.1097/ID.0000000000000478

28. Guobis Z, Pacauskiene I, Astramskaite I. General diseases influence on peri-implantitis development: a systematic review. J Oral Maxillofac Res. 2016 Sep;7(3):e5. https://doi.org/10.5037/jomr.2016.7305

29. Naujokat H, Kunzendorf B, Wiltfang J. Dental implants and diabetes mellitus-a systematic review. Int J Implant Dent. 2016 Dec;2(1):5. https://doi.org/10.1186/s40729-016-0038-2PMID:27747697

30. Turri A, Rossetti PH, Canullo L, Grusovin MG, Dahlin C. Prevalence of peri-implantitis in medically compromised patients and smokers: a systematic review. Int J Oral Maxillofac Implants. 2016 Jan-Feb;31(1):111-8. https://doi.org/10.11607/jomi.4149

31. Loo W, Jin L, Cheung M, Wang M. The impact of diabetes on the success of dental implants and periodontal healing. Afr J Biotechnol. 2009;8(19):5122-7.

32. Moraschini V, Poubel LA, Ferreira VF, Barboza ES. Evaluation of survival and success rates of dental implants reported in longitudinal studies with a follow-up period of at least 10 years: a systematic review. Int J Oral Maxillofac Surg. 2015 Mar;44(3):377-88. https://doi.org/10.1016/i.ijom.2014.10.023

33. Hjalmarsson L, Gheisarifar M, Jemt T. A systematic review of survival of single implants as presented in longitudinal studies with a follow-up of at least 10 years. Eur J Oral Implantol. 2016;9 Suppl 1:S155-62.

34. Kocher T, König J, Borgnakke WS, Pink C, Meisel P. Periodontal complications of hyperglycemia/diabetes mellitus: epidemiologic complexity and clinical challenge. Periodontol 2000. 2018 Oct;78(1):59-97. https://doi.org/10.1111/prd.12235 